\title{
The elderly cancer patient: the interplay between age and clinical decision-making
}

\author{
Tanya Di Valentin, Timothy Asmis \\ Ottawa Regional Cancer Center, Ottawa, Ontario, Canada \\ Correspondence:Tanya Di Valentin. Address: Medical Oncology Training Program, University of Ottawa, The Ottawa \\ Hospital Cancer Center, 501 Smyth Road, Box900, Ottawa, Canada. Telephone: 613-798-5555 Ext 78-222. Fax: \\ 613-247-3528. E-mail: tdivalentin@Ottawahospital.on.ca
}

Received: March 30, 2012

Accepted: June 25, $2012 \quad$ Published: August 1, 2012

DOI : $10.5430 /$ jst.v2n4p63

URL: http://dx.doi.org/10.5430/jst.v2n4p63

\begin{abstract}
Oncology affects millions of elderly patients. Despite this significant and growing population, there are few randomized trials in geriatric oncology. As a result, the treatment of this age group is often controversial. The physician often faces many unanswered questions regarding the best treatment strategy for his or her elderly patients. This article aims to demonstrate how the lack of research in the area of geriatric oncology represents a barrier to treatment decisions. Further, we will describe the interaction between age, comorbidity and cancer, and how these variables can affect treatment and outcomes in the elderly.
\end{abstract}

\section{Key words}

Elderly cancer patient, Treatment decisions, Chemotherapy, Performance status, Clinical trials, The elderly

\section{Introduction}

Over the past decades, the life expectancy of the general population has increased ${ }^{[1]}$. It is therefore common that many physicians encounter a significant proportion of elderly patients in their day to day practice. In oncology, a patient's age is often the subject of much debate, as health care providers are often faced with the dilemma of how best to manage cancer in the elderly population.

This article aims to investigate the role and interaction of age, comorbidity and performance status with the management and outcomes of cancer in the elderly population.

\section{Comorbities and cancer}

Advancing age is directly related to the development of cancer. It is also directly related to an increase in the number of other health problems ${ }^{[2,3]}$. As patients age, they are more prone to suffer from a variety of health issues. On average, cancer patients aged 70 or more suffer from three comorbidities ${ }^{[4]}$. Comorbidities not only directly affect a patient's health, but can also influence how cancer is detected, managed, and how it evolves. 
Many comorbidity scales exist to help measure the health and performance status of cancer patients. However, the Charslon Comorbidity Index (CCI) ${ }^{[5,6]}$ is one of the most widely accepted methods as it is the most simple and has been validated. It has been shown to have prognostic value in lung, colorectal, breast, head and neck, and prostate cancers ${ }^{[7-9]}$. However, there is still some debate as to whether the CCI is indeed the main factor influencing outcomes in the elderly and whether it is appropriate to use this index to curtail cancer treatments (i.e., inclusion, exclusion or dose modification of cancer treatment in the elderly).

There are few studies examining treatment outcomes in the elderly because this population is often excluded or under-represented in clinical trials ${ }^{[10,11]}$. However, there have been various reviews aimed at investigating what factors are the most important when treating an aging population ${ }^{[12]}$.

The study of comorbidities in the elderly and the impact of these on treatment outcome have yielded conflicting results. A number of studies have revealed that there is little association between a patient's CCI and overall survival ${ }^{[13,14]}$. By contrast, other studies have demonstrated that comorbities negatively impact survival in cancer patients ${ }^{[15,16]}$. The lack of extensive prospective data on this topic contributes to confusion in clinical practice and has resulted in no clinical guidelines. The physician is left with conflicting information regarding the impact of comorbidities and must recommend treatment for elderly patients without the help of firm guidelines.

\section{Treatment outcomes in the elderly}

While there are few randomized trials in geriatric oncology, a number of studies have demonstrated a lack of an association between age and cancer treatment outcome ${ }^{[15,17-19]}$. Although there is a direct association between age and the number of comorbidities, the literature reveals that it is an individual's overall performance status rather than age or specific health problems that correlate with overall survival. This holds true for different tumor sites ${ }^{[13,20]}$. Although there is a complex interplay between comorbidity and performance status, these variables are not always concordant. Thus, it is important that physicians not confuse these variables when making treatment decisions. For example, downgrading a patient's performance status simply because they suffer from significant comorbidities may result in the exclusion of appropriate treatment candidates.

The role of age on clinical decision-making is one that is seen in a number of different tumor sites. For example, the optimal treatment of localized prostate cancer in elderly patients remains controversial ${ }^{[21]}$. Current expert guidelines ${ }^{[22,23]}$ and various studies of older men believed to have less than 10 years life expectancy suggest that conservative management with observation or androgen deprivation rather than radical treatment is a viable option ${ }^{[24,25]}$. By contrast, there is evidence that older men may be undertreated simply based on their age ${ }^{[26,27]}$. Thompson and colleagues investigated outcomes of octogenarians who underwent radical prostatectomy to treat their early stage prostate cancer. Their findings revealed that carefully selected elderly patients can indeed benefit from radical treatment just as their younger counterparts do ${ }^{[28]}$. This is consistent with the study of gastric cancer patients by Saif et al which demonstrated that fit elderly patients benefitted from curative and palliative treatment in the forms of surgery and chemotherapy to the same extent as their younger counterparts ${ }^{[29]}$.

With regards to the operative risk surrounding cancer surgeries, some studies have shown that elderly patients have higher pre-operative risks, mostly attributable to their existing co morbidities ${ }^{[30]}$. By contrast, there is conflicting data on postoperative mortality when event rates (i.e. postoperative morbidity and mortality) in the elderly and the younger populations. More specifically, some series indicated that elderly patients benefitted from surgery and had similar outcomes as their younger counterparts. Conversely, other data reveals that complications occur at higher rates in the elderly ${ }^{[31-33]}$. To better understand surgical outcomes in this age group, large clinical trials examining the association between patient co-morbidities, age and postoperative results are required. 


\section{Clinical trials and the elderly}

Cancer in the elderly is a significant problem. Review of epidemiological SEER data ${ }^{[34]}$ reveals that between 2004-2008, the median age of cancer diagnosis for all sites was 66 . Furthermore, approximately $54 \%$ of cancer cases occurred in patients aged 65 or more, and $70 \%$ of cancer-related deaths occurred in this age group. In fact, elderly individuals have a tenfold risk of getting cancer, and are 15 times more likely to die from cancer than individuals under age 65 . Despite the propensity of this disease in the geriatric population, the elderly remain an age group that is underrepresented in oncologic studies.

One of the main difficulties with making firm recommendations regarding the treatment of the elderly cancer patient is the fact that most clinical trials exclude individuals of advanced age due to the strict selection criteria of trial design ${ }^{[35,36]}$.

Although there are few, some studies specifically looked at treatment outcomes in the elderly. Importantly, there is some data showing that elderly patients who meet the inclusion criteria of clinical trials experience benefits and toxicities of treatment similar to those experienced by younger patients ${ }^{[15,29,37]}$. For example, in the pivotal MAGIC trial ${ }^{[38]}$, gastric cancer patients were randomized to pre- and postoperative chemotherapy (3 cycles of epirubicin-cisplatin-5FU pre and postoperatively) versus surgery alone. In this study, $20 \%$ of patients that received the preoperative chemotherapy were 70 or older. Just like the younger patients included in the MAGIC trial, this subgroup of patients experienced significant improvements in overall survival and progression-free survival.

Similarly, the ELVIS study ${ }^{[39]}$, which studied lung cancer, illustrated that elderly patients over 70 years of age deemed fit enough, did better with chemotherapy than with best supportive care alone. Similarly in lung cancer, the MILES study revealed that elderly patients (over 70 years old) benefitted not only from treatment, but had better outcomes when treated with combination chemotherapy rather than a single agent ${ }^{[40]}$. These studies illustrate the important point that an elderly cancer patient can indeed benefit from treatment, and should not be excluded solely based on age.

As a result of the underrepresentation of the elderly in clinical trials, most of the data relied on by physicians in making treatment decisions comes from retrospective reviews ${ }^{[36]}$. Thus there is little direct information on the interaction of comorbidity, age, and functional status and treatment outcomes. Given the lack of firm recommendations for treatment of the elderly population, this often leaves the physician in a position of trying to extrapolate the best treatment regimen from results that were not thoroughly investigated in this population.

The lack of data for the elderly illustrates the need for more defined methods to determine when to include or exclude these individuals. Trial designs should outline defined parameters recognizing that an elderly patient with a good functional status, even if they have certain comorbidities, may be a more suitable candidate than a patient, elderly or not, that has a worse performance status, even if they have no comorbidities. This however is not an easy task, as the interplay between all these variables is complex.

Performance status is something that can be assessed relatively easily, as this is one variable that quickly allows the physician to determine the capacity of the individual to withstand treatment or not. The ECOG performance status scale ${ }^{[41]}$ is easily applied on a universal level and leaves little room for different interpretation between physicians.

By contrast, co-morbidities and their present or future impacts are much more difficult to define. Different health care providers have different tolerances as to how they grade the severity of diseases. For example, some physicians may treat a patient because they have experience dealing with certain comorbidities and have seen positive results in certain patients afflicted with the same diseases. Conversely, others may automatically exclude a patient with certain comorbidity for a variety of reasons (i.e. lack of experience in dealing with the interaction of the comorbidity and cancer treatment, previous adverse events in patients with a particular disease, etc.) ${ }^{[8,42,43]}$. The difficulty herein is that unlike functional status, that integrates multiple aspects that can affect the health of an individual, (i.e. the effects of comorbidities on the patients' 
health, fitness level, BMI, age, etc.) co-morbidities and their potential effect on the patient and the success of the treatment are much more difficult to evaluate and grade.

Further complicating the importance of comorbidity in cancer treatment is data suggesting that other health problems may actually confer some protection against acquiring cancer. Some data has shown that hypothyroidism was associated with a lower incidence of breast cancer ${ }^{[2]}$. Other research ${ }^{[44]}$ demonstrated that allergies and autoimmune related diseases (diabetes being one of them) were associated with a decreased incidence of gliomas and meningiomas. However, there is no data to show how individuals with these diseases, once diagnosed with cancer, compare to those without these "protective" comorbidities. Nevertheless, this data demonstrates the complexities surrounding comorbidities and the uncertainty surrounding its impact on the incidence and evolution of cancer.

\section{Conclusion}

As our population ages, geriatric oncology is a field that oncologists will encounter on an increasing basis. Past practices of excluding individuals from trials solely based on their age is no longer appropriate. As various studies have demonstrated, age is often unrelated to outcome. Rather, functional status seems to be a more accurate marker of how patients will do with treatment. Since little research has been done in the elderly population, more data, including some from large randomized controlled studies, is warranted. This information is necessary for physicians to develop appropriate firm recommendations for the treatment of elderly patients. Geriatric oncology remains a challenging field that requires further exploration.

\section{References}

[1] Organization, W.H. and E. al. Global Health Observatory Data Repository [Internet]. 2012. Available from: http://www.who.int/research/en/.

[2] Extermann, M., Interaction between comorbidity and cancer. Cancer control: journal of the Moffitt Cancer Center. 2007; 14(1): $13-22$.

[3] Jemal, A., et al., Cancer statistics, 2009. CA: a cancer journal for clinicians. 2009; 59(4): 225-49. PMid:19474385 http://dx.doi.org/10.3322/caac.20006

[4] Extermann, M., et al., Comorbidity and functional status are independent in older cancer patients. Journal of clinical oncology: official journal of the American Society of Clinical Oncology. 1998; 16(4): 1582-7.

[5] Charlson, M.E., et al., A new method of classifying prognostic comorbidity in longitudinal studies: development and validation. Journal of chronic diseases. 1987; 40(5): 373-83. http://dx.doi.org/10.1016/0021-9681(87)90171-8

[6] Charlson, M., et al., Validation of a combined comorbidity index. Journal of clinical epidemiology. 1994; 47(11): $1245-51$. http://dx.doi.org/10.1016/0895-4356(94)90129-5

[7] Klabunde, C.N., et al., A refined comorbidity measurement algorithm for claims-based studies of breast, prostate, colorectal, and lung cancer patients. Annals of epidemiology. 2007; 17(8): 584-90. PMid:17531502

http://dx.doi.org/10.1016/j.annepidem.2007.03.011

[8] Gosney, M.A., Clinical assessment of elderly people with cancer. The lancet oncology. 2005; 6(10): 790-7. http://dx.doi.org/10.1016/S1470-2045(05)70389-2

[9] Hall, W.H., et al., An electronic application for rapidly calculating Charlson comorbidity score. BMC cancer. 2004 ; 4 : 94. PMid:15610554 http://dx.doi.org/10.1186/1471-2407-4-94

[10] Monfardini, S., et al., Entry and evaluation of elderly patients in European Organization for Research and Treatment of Cancer (EORTC) new-drug-development studies. Cancer. 1995; 76(2): 333-8. http://dx.doi.org/10.1002/1097-0142(19950715)76:2<333::AID-CNCR2820760226>3.0.CO;2-I

[11] Trimble, E.L., et al., Representation of older patients in cancer treatment trials. Cancer. 1994; 74(7 Suppl): $2208-14$. http://dx.doi.org/10.1002/1097-0142(19941001)74:7+<2208::AID-CNCR2820741737>3.0.CO;2-\#

[12] Extermann, M., Measurement and impact of comorbidity in older cancer patients. Critical reviews in oncology/hematology. 2000; 35(3): 181-200. http://dx.doi.org/10.1016/S1040-8428(00)00090-1 
[13] Asmis, T.R., et al., Comorbidity, age and overall survival in cetuximab-treated patients with advanced colorectal cancer (ACRC)--results from NCIC CTG CO.17: a phase III trial of cetuximab versus best supportive care. Annals of oncology: official journal of the European Society for Medical Oncology / ESMO. 2011; 22(1): 118-26.

[14] Vickers, M.M., et al., Comorbidity, age and overall survival in patients with advanced pancreatic cancer - Results from NCIC CTG PA.3: A phase III trial of gemcitabine plus erlotinib or placebo. European journal of cancer. 2011.

[15] Asmis, T.R., et al., Age and comorbidity as independent prognostic factors in the treatment of non-small-cell lung cancer: a review of National Cancer Institute of Canada Clinical Trials Group trials. Journal of clinical oncology: official journal of the American Society of Clinical Oncology. 2008; 26(1): 54-9.

[16] Meyerhardt, J.A., et al., Impact of diabetes mellitus on outcomes in patients with colon cancer. Journal of clinical oncology: official journal of the American Society of Clinical Oncology. 2003; 21(3): 433-40.

[17] Sanoff, H.K., H. Bleiberg, and R.M. Goldberg, Managing older patients with colorectal cancer. Journal of clinical oncology: official journal of the American Society of Clinical Oncology. 2007; 25(14): 1891-7.

[18] Goldberg, R.M., et al., Pooled analysis of safety and efficacy of oxaliplatin plus fluorouracil/leucovorin administered bimonthly in elderly patients with colorectal cancer. Journal of clinical oncology: official journal of the American Society of Clinical Oncology. 2006; 24(25): 4085-91.

[19] D'Andre, S., et al., 5-Fluorouracil-based chemotherapy for advanced colorectal cancer in elderly patients: a north central cancer treatment group study. Clinical colorectal cancer. 2005; 4(5): 325-31. PMid:15663836 http://dx.doi.org/10.3816/CCC.2005.n.005

[20] Janssen-Heijnen, M.L., et al., Effect of comorbidity on the treatment and prognosis of elderly patients with non-small cell lung cancer. Thorax. 2004; 59(7): 602-7. PMid:15223870 http://dx.doi.org/10.1136/thx.2003.018044

[21] Stangelberger, A., M. Waldert, and B. Djavan, Prostate cancer in elderly men. Reviews in urology. 2008; 10(2): 111-9. PMid:18660852

[22] Chodak, G.W., et al., Results of conservative management of clinically localized prostate cancer. The New England journal of medicine. 1994; 330(4): 242-8. PMid:8272085 http://dx.doi.org/10.1056/NEJM199401273300403

[23] Albertsen, P.C., J.A. Hanley, and J. Fine, 20-year outcomes following conservative management of clinically localized prostate cancer. JAMA: the journal of the American Medical Association. 2005; 293(17): 2095-101. PMid:15870412 http://dx.doi.org/10.1001/jama.293.17.2095

[24] Johansson, J.E., et al., Fifteen-year survival in prostate cancer. A prospective, population-based study in Sweden. JAMA: the journal of the American Medical Association. 1997; 277(6): 467-71. http://dx.doi.org/10.1001/jama.1997.03540300035030

[25] Ruchlin, H.S. and J.M. Pellissier, An economic overview of prostate carcinoma. Cancer. 2001; 92(11): $2796-810$. http://dx.doi.org/10.1002/1097-0142(20011201)92:11<2796::AID-CNCR10124>3.0.CO;2-R

[26] Alibhai, S.M., et al., Is there age bias in the treatment of localized prostate carcinoma? Cancer. 2004; 100(1): 72-81. PMid:14692026 http://dx.doi.org/10.1002/cncr.11884

[27] Schwartz, K.L., et al., Continued undertreatment of older men with localized prostate cancer. Urology, 2003; 62(5): 860-5. http://dx.doi.org/10.1016/S0090-4295(03)00690-3

[28] Thompson, R.H., et al., Radical prostatectomy for octogenarians: how old is too old? Urology. 2006; 68(5): 1042-5. PMid:17095073 http://dx.doi.org/10.1016/j.urology.2006.05.031

[29] Saif, M.W., et al., Gastric cancer in the elderly: an overview. European journal of surgical oncology: the journal of the European Society of Surgical Oncology and the British Association of Surgical Oncology. 2010; 36(8): 709-17.

[30] Seo, S.H., et al., Operative risk factors in gastric cancer surgery for elderly patients. Journal of gastric cancer, 2011; 11(2): 116-21.

[31] Coniglio A, et al., Surgical treatment for gastric carcinoma in the elderly. J Sug Oncol. 2004; 88: 201-5. PMid:15565628 http://dx.doi.org/10.1002/jso.20153

[32] Orsenigo, E., et al., Impact of age on postoperative outcomes in 1118 gastric cancer patients undergoing surgical treatment. Gastric cancer: official journal of the International Gastric Cancer Association and the Japanese Gastric Cancer Association. 2007; 10(1): 39-44.

[33] Kunisaki, C., et al., Comparison of surgical outcomes of gastric cancer in elderly and middle-aged patients. American journal of surgery. 2006; 191(2): 216-24. PMid:16442949 http://dx.doi.org/10.1016/j.amjsurg.2005.09.001

[34] Howlader, N., et al. SEER Cancer Statistics Review, 1975-2008. 2011; Available from: http://seer.cancer.gov/csr/1975_2008/.

[35] Repetto, L., L. A. Venturino, and D.S. Fratino, G. Troisi, W. Gianni, M. Pietropaolo, Geriatric oncology: a clinical approach to the older patient with cancer. European Journal of Cancer. 2003 May; 39(7): 870-880.

http://dx.doi.org/10.1016/S0959-8049(03)00062-5

[36] Hutchins, L.F., et al., Underrepresentation of patients 65 years of age or older in cancer-treatment trials. The New England journal of medicine. 1999; 341(27): 2061-7. PMid:10615079 http://dx.doi.org/10.1056/NEJM199912303412706 
[37] langer, C.J., et al. Age-specific subanalysis of ECOG 1594: Fit elderly patients (70-80 YRS) with NSCLC do as well as younger patients (<70). In Proc AM Soc Clin Oncol. 2003.

[38] Cunningham, D., et al., Perioperative chemotherapy versus surgery alone for resectable gastroesophageal cancer. The New England journal of medicine. 2006; 355(1): 11-20. PMid:16822992 http://dx.doi.org/10.1056/NEJMoa055531

[39] Gridelli, C., The ELVIS trial: a phase III study of single-agent vinorelbine as first-line treatment in elderly patients with advanced non-small cell lung cancer. Elderly Lung Cancer Vinorelbine Italian Study. The oncologist. 2001; 6 Suppl 1: 4-7. PMid:11181997 http://dx.doi.org/10.1634/theoncologist.6-suppl_1-4

[40] Gridelli, C., et al., Chemotherapy for elderly patients with advanced non-small-cell lung cancer: the Multicenter Italian Lung Cancer in the Elderly Study (MILES) phase III randomized trial. Journal of the National Cancer Institute. 2003; 95(5): 362-72. http://dx.doi.org/10.1093/jnci/95.5.362

[41] Oken, M.M., et al., Toxicity and response criteria of the Eastern Cooperative Oncology Group. American journal of clinical oncology. 1982; 5(6): 649-55. PMid:7165009 http://dx.doi.org/10.1097/00000421-198212000-00014

[42] Balducci, L., Geriatric oncology: challenges for the new century. European journal of cancer. 2000; 36(14): 1741-54. http://dx.doi.org/10.1016/S0959-8049(00)00169-6

[43] Balducci, L. and M. Extermann, Management of cancer in the older person: a practical approach. The oncologist. 2000; 5(3): 224-37. PMid:10884501 http://dx.doi.org/10.1634/theoncologist.5-3-224

[44] Schwartzbaum, J., et al., Cohort studies of association between self-reported allergic conditions, immune-related diagnoses and glioma and meningioma risk. International journal of cancer. Journal international du cancer. 2003; 106(3): 423-8. 